\title{
Biomechanics of a cemented short stem: a comparative in vitro study regarding primary stability and maximum fracture load
}

\author{
Tobias Freitag $^{1} \cdot$ Karl Philipp Kutzner $^{2} \cdot$ Ralf Bieger $^{1} \cdot$ Heiko Reichel $^{1} \cdot$ Anita Ignatius $^{3} \cdot$ Lutz Dürselen $^{3}$
}

Received: 14 July 2020 / Accepted: 20 February 2021 / Published online: 23 March 2021

(c) The Author(s) 2021

\begin{abstract}
Purpose In total hip arthroplasty, uncemented short stems have been used more and more frequently in recent years. Especially for short and curved femoral implants, bone-preserving and soft tissue-sparing properties are postulated. However, indication is limited to sufficient bone quality. At present, there are no curved short stems available which are based on cemented fixation.

Methods In this in vitro study, primary stability and maximum fracture load of a newly developed cemented short-stem implant was evaluated in comparison to an already well-established cemented conventional straight stem using six pairs of human cadaver femurs with minor bone quality. Primary stability, including reversible micromotion and irreversible migration, was assessed in a dynamic material-testing machine. Furthermore, a subsequent load-to-failure test revealed the periprosthetic fracture characteristics.

Results Reversible and irreversible micromotions showed no statistical difference between the two investigated stems. All short stems fractured under maximum load according to Vancouver type B3, whereas 4 out of 6 conventional stems suffered a periprosthetic fracture according to Vancouver type C. Mean fracture load of the short stems was $3062 \mathrm{~N}$ versus $3160 \mathrm{~N}$ for the conventional stems $(p=0.84)$.

Conclusion Primary stability of the cemented short stem was not negatively influenced compared to the cemented conventional stem and no significant difference in fracture load was observed. However, a clear difference in the fracture pattern has been identified.
\end{abstract}

Keywords Cemented total hip arthroplasty $\cdot$ Short stem $\cdot$ Biomechanics $\cdot$ Migration $\cdot$ Micromotion $\cdot$ Primary stability $\cdot$ Fracture pattern $\cdot$ Cadaver

\section{Introduction}

Cemented total hip arthroplasty (THA) has a long history of success, being a safe strategy for the treatment especially for elderly patients with potentially reduced bone quality [1]. Registry data from Sweden, Norway and England show

Tobias Freitag

tobias.freitag@rku.de

1 Department of Orthopaedic Surgery, University of Ulm, Oberer Eselsberg 45, 89081 Ulm, Germany

2 Department of Orthopaedic Surgery and Traumatology, St. Josefs Hospital Wiesbaden, Beethovenstr. 20, 65189 Wiesbaden, Germany

3 Institute of Orthopaedic Research and Biomechanics, Trauma Research Centre Ulm, Ulm University, Medical Centre, Helmholtzstr. 14, 89081 Ulm, Germany a better long-term survivorship of cemented compared to cementless implant fixation [2-4]. Data from the national registries in Australia and New Zealand characterize a lower revision rate of cemented compared to cementless stems, especially in female patients over 75 years [5, 6]. Femoral periprosthetic fractures following THA remain one of the leading causes of early failure requiring revision surgery [7-9]. In this regard, the main risk factors are reduced bone quality, advanced age and female gender $[8,10]$. Consequently, cemented femoral stem fixation is strongly correlated with a decreased risk of early periprosthetic fractures of the femur, particularly in female and elderly populations $[11,12]$.

In the last decade, there has been a trend towards the development of shorter cementless femoral implants, aiming to enable a more bone- and soft tissue-sparing implantation technique [13-15]. Most implants of the latest generation 
provide a curved stem design, which allows the implantation without compromising the trochanteric region and thus the pelvitrochanteric structures. Promising medium- and longterm term data already exist for several shorter cementless implant models [16, 17]. Some authors confirm advantageous results regarding perioperative blood loss and a lower intraoperative complication rate compared to standard implants [18-20]. On the other hand, some authors propagate a limitation of this implant group, especially in poor bone quality, due to the shorter and ostensibly metaphyseal fixation [21, 22]. A markedly reduced bone quality was seen to be associated with a dramatically increased risk for postoperative periprosthetic femoral fractures using a cementless calcar-guided short stem [23]. Taking this contraindication into account, implant survival rates up to $100 \%$ at 8 years have been reported [24].

Currently, efforts are being made to transfer the postulated potential advantages of uncemented short-stem THA to the concept of a cemented short stem, providing the same philosophy, to extend the range of indications to a patient collective with reduced bone quality [25]. To date, no curved short stem, providing cemented fixation, is officially available on the market.

The aim of this in vitro study was to compare primary stability and fracture load of a newly developed, cemented curved short stem with an already well-established cemented conventional stem [26].

\section{Methods}

\section{Implants}

The prototype of the cemented optimys short stem (Fig. 1) is based on the design of the uncemented implant, which is available on the market since 2010 (optimys, Mathys Ltd., Bettlach, Switzerland). According to the concept of many successful cemented conventional stems on the market, the prototype is made of polished wrought high nitrogen stainless steel for implants based on ISO 5832-1. With 13 selectable sizes the stem length is between 80 and $118 \mathrm{~mm}$. As a reference, the well-established cemented conventional straight twinSys stem (ODEP 7A*) was used in this study (twinSys, Mathys Ltd., Bettlach, Switzerland). The stem is available in 8 sizes with lengths between 140 and $170 \mathrm{~mm}$ (Fig. 1).

Both implants provide a triple taper design, which converts shear forces into compression forces and thus allows the stem to wedge into the cement mantle. Two different offset versions are available for both implants, standard and lateralized, for offering a broad offset range to reconstruct the individual femoral offset. An earlier study of our group showed no inferiority in terms of primary stability and maximum fracture load of the cemented short-stem prototype, using a line-to-line cementation technique, compared to a standard technique using an undersized stem [25]. Thus, a line-to-line cementation technique was used. In contrast, the design of the conventional stem used for this study, is undersized by $1 \mathrm{~mm}$ compared to the final rasp and thus, offers a minimal space for a preferably homogeneous cement mantle.

\section{Preparation of cadaver femurs}

After institutional review board approval, six osteoporotic pairs of fresh-frozen human femurs were obtained via ScienceCare (Phoenix, AZ, USA). All donors were female, with a mean age of 71 years (range 63-81 years) and a mean Body Mass Index (BMI) of $30.2 \mathrm{~kg} / \mathrm{m}^{2}$ (range $18.9-42.6 \mathrm{~kg} / \mathrm{m}^{2}$ ) (Table 1). Radiographs in two planes ruled out any malignant neoplasia or fractures. Digital 2D templating, using the original stem templates, estimated the size and positioning of the required femoral implants as well as the height of the neck resection. Minor bone quality was confirmed using dual-energy X-ray absorptiometry (DEXA) measurement [mean $T$-score: -1.8 (range: -3.0 to -0.7 )]. Specimen preparation included soft tissue removal and shortening to an equal length of $37 \mathrm{~cm}$ below the tip of the greater trochanter. Before cutting the femoral condyles, neck anteversion was recorded for subsequent orientation. Finally, specimens were fixed in a steel cup using Polymethylmethacrylate (Technovit 3040; Heraeus Kulzer, Wehrheim, Germany). The femur was tilted laterally by $8^{\circ}$ in the frontal plane and by $6^{\circ}$ dorsally in the sagittal plane to simulate single-leg stance and to create bending and torsional moments as previously described [25, 27] (Fig. 2).

\section{Implantation and cementation technique}

The implantation of the investigated implants was performed alternating, either in the right or the left of six pairs of femurs, by an experienced orthopedic surgeon (TF) according to the manufacturer's specifications. A third-generation cementing technique was used. A cement restrictor (BonePlug PE, Mathys Ltd., Bettlach, Switzerland) was inserted, to occlude the femoral canal, providing $1 \mathrm{~cm}$ distance to the tip of the stem. Before implantation, cleaning of the femoral cavity was performed using a Jet Lavage system (InterPulse, Stryker Corp., USA). It was then thoroughly dried. One unit (40 g) of Palacos R $+\mathrm{G}$ bone cement (Heraeus Medical, Hanau, Germany) was vacuum mixed and applied in retrograde fashion via cement gun and pressurized using a femoral seal [28]. The implants were inserted manually and pressure was maintained until the cement was set. 
Fig. 1 Cemented optimys (left), and twinSys stem (Mathys Ltd., Bettlach, Switzerland)
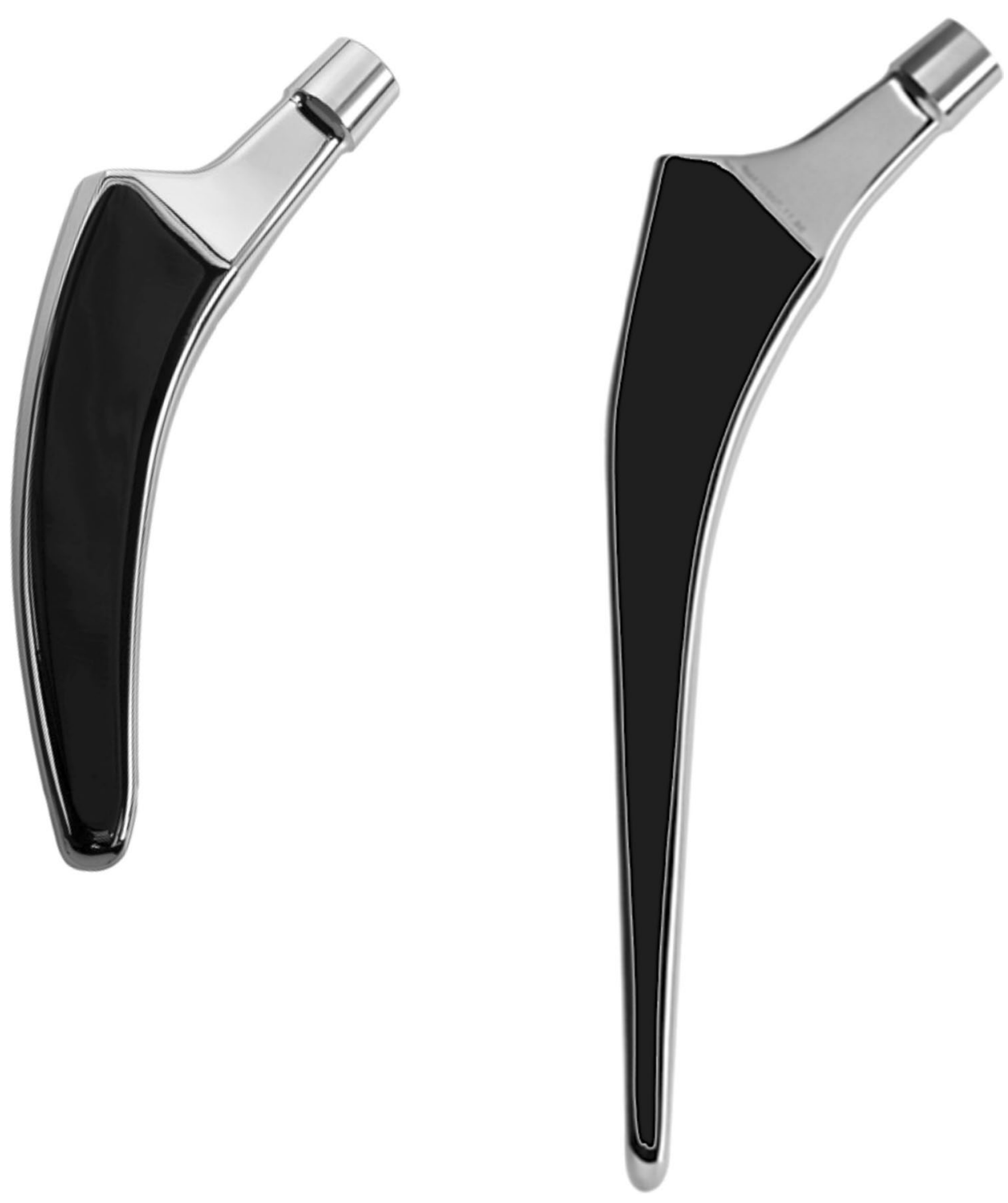

Table 1 Demographics of donors

\begin{tabular}{llllllllll}
\hline Specimen & Side & Age & Height $(\mathrm{m})$ & Weight $(\mathrm{kg})$ & BMI & Sex & $T$-score & Implant & Implant size \\
\hline 1 & $\mathrm{r}$ & 63 & 1.52 & 98.9 & 42.6 & $\mathrm{f}$ & -1.5 & TwinSys & 13 \\
1 & 1 & & & & & & -1.9 & Optimys & 5 \\
2 & $\mathrm{r}$ & 63 & 1.63 & 49.9 & 18.9 & $\mathrm{f}$ & -2.1 & Optimys & 5 \\
2 & 1 & & & & & & -2.2 & TwinSys & 14 \\
3 & $\mathrm{r}$ & 70 & 1.57 & 99.8 & 40.2 & $\mathrm{f}$ & -1.2 & TwinSys & 12 \\
3 & 1 & & & & & & -0.7 & Optimys & 5 \\
4 & $\mathrm{r}$ & 80 & 1.68 & 108.9 & 38.7 & $\mathrm{f}$ & -1.5 & Optimys & 5 \\
4 & 1 & & & & & & -1.3 & TwinSys & 12 \\
5 & $\mathrm{r}$ & 69 & 1.57 & 49.9 & 20.1 & $\mathrm{f}$ & -1.4 & TwinSys & 12 \\
5 & 1 & & & & & & -2.3 & Optimys & 5 \\
6 & 1 & 81 & 1.57 & 51.7 & 20.9 & $\mathrm{f}$ & -3 & TwinSys & 14 \\
6 & $\mathrm{r}$ & & & & & & -2.5 & Optimys & 6 \\
\hline
\end{tabular}




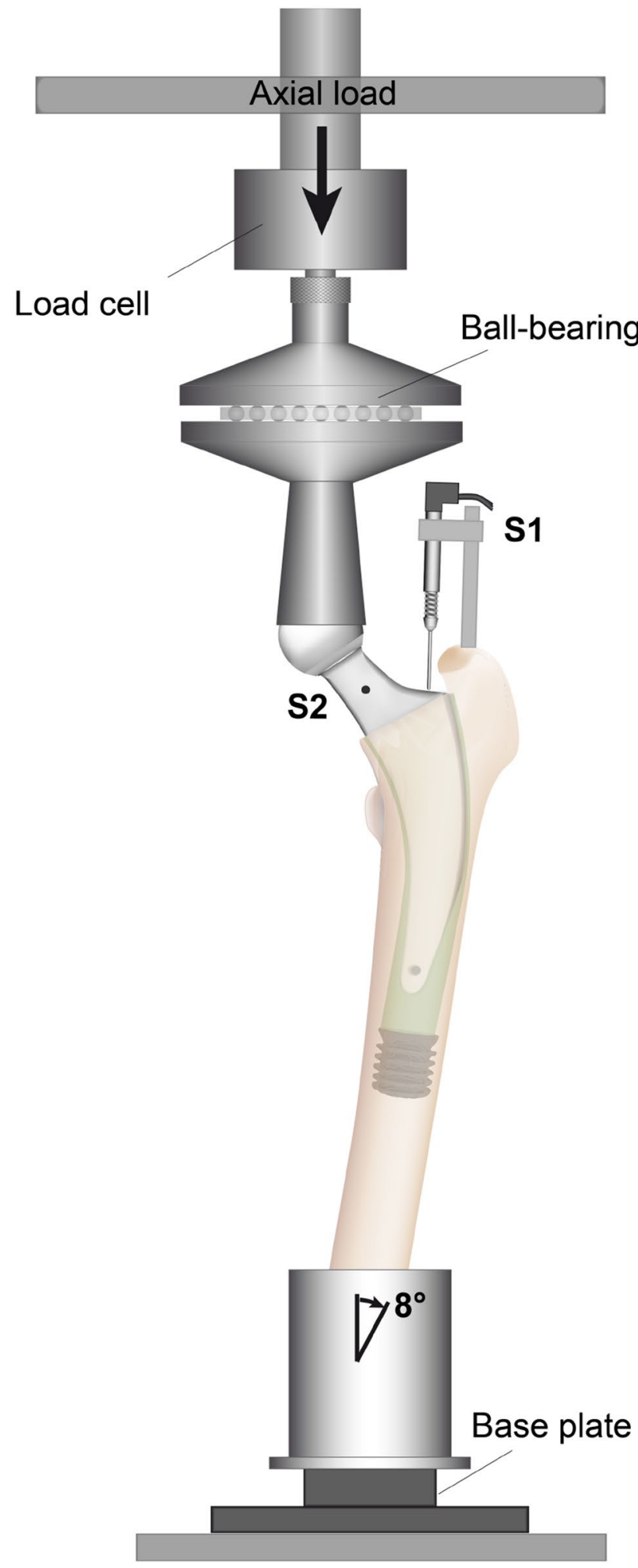

Fig. 2 The test setup. S1 and S2 demonstrate the locations of the two miniature displacement transducers
Measurement of primary stability under dynamic loading

For measurement of relative motion between the implant and the cortical bone, two inductive miniature displacement transducers (HBM WI/5 mm-T; HBM, Darmstadt, Germany) with a precision of $1 \mu \mathrm{m}$ were attached to the cortical bone. Relative axial implant-bone motion was measured at transducer S1 at the shoulder of the prosthesis (Fig. 2). Rotational stem motion was captured at transducer S2, which was attached perpendicular to the neck of the implant (Fig. 2). The measured micromotions were calculated into rotation around the femoral axis by gauging the distance between the tip of the transducer and the longitudinal axis of the femoral diaphysis [29]. The femur was mounted in a servo hydraulic material-testing machine (Instron, Typ 8871, Pfungstadt, Germany), which applied a vertical load. A ball bearing was attached between the device and the load cell to achieve a moment-free introduction of the load (Fig. 2). The material-testing machine applied 100,000 dynamic sinusoidal load cycles at a frequency of $2 \mathrm{~Hz}$ between 100 and $1600 \mathrm{~N}$ to simulate the load of the first 6 weeks in vivo [30]. Reversible implantbone motion was captured every 500 cycles at the two measurement points for all samples. Furthermore, irreversible implant migration in axial direction (S1) was calculated by the displacement between the initial implant position and the position at the end of 100,000 loading cycles. In the same way, irreversible torsion around the femoral axis was calculated from the displacement assessed at transducer S2.

\section{Assessment of fracture load and fracture pattern}

After dynamic loading, repeated radiographs in two planes were performed to exclude periprosthetic fractures of specimens. Subsequently, specimens were transferred to the testing machine and linearly loaded at a rate of $100 \mathrm{~N} / \mathrm{s}$ under load control until a fracture occurred. The fracture load (Fmax) was assessed and fracture pattern was analyzed using the Vancouver Classification [32].

\section{Statistical analysis}

Statistical analysis was performed using SAS 9.4 software (SAS Institute, Cary, NC). Normality testing indicated that the data were non-parametric in nature and so testing was performed using Wilcoxon signed-rank to analyze differences of reversible and irreversible micromotions as well as of fracture loads between the two implants. Significance was assumed for $p \leq 0.05$. 


\section{Results}

\section{Reversible micromotion measurement}

After 100,000 loading cycles mean micromotion amplitudes at both transducer locations did not display any statistical differences between both femoral implants. Mean axial micromotions were $5.3 \mu \mathrm{m}$ (SD $3.9 \mu \mathrm{m}$ ) for the short stem in comparison to $9.3 \mu \mathrm{m}$ (SD $6.6 \mu \mathrm{m}$ ) for the conventional stem $(p=0.23)$. The calculated rotation around the femoral axis was in direction of retroversion for both stems, with values of $0.03^{\circ}\left(\mathrm{SD} 0.02^{\circ}\right.$ ) for the short stem and $0.04^{\circ}$ (SD $\left.0.02^{\circ}\right)$ for the conventional stem $(p=0.44$; Table 2$)$.

\section{Irreversible migration measurement}

Mean axial migration after 100,000 loading cycles was $-20.4 \mu \mathrm{m}$ (SD $38.3 \mu \mathrm{m}$ ) for the short stem and $-61.4 \mu \mathrm{m}$ (SD $92.8 \mu \mathrm{m})$ for the conventional stem $(p=0.22)$. Only minor rotation towards retroversion was measured, with $0.003^{\circ}\left(\mathrm{SD} 0.04^{\circ}\right)$ for the short stem and $0.09^{\circ}\left(\mathrm{SD} 0.12^{\circ}\right)$ for the conventional stem $(p=0.09)$ with a tendency towards less retroversion in the group of the short stems (Table 2).

\section{Maximum fracture load and fracture pattern}

Mean maximum fracture load (Fmax) to induce a periprosthetic fracture was $3062 \mathrm{~N}(\mathrm{SD} 332 \mathrm{~N})$ in the short-stem group, whereas Fmax load of 3160 N (SD 544 N) induced a fracture in the conventional stem group (Table 3 ). No significant differences in Fmax load between the short and conventional stems were found $(p=0.84)$.

All short stems fractured under maximum load according to Vancouver type B3 (stem loose, poor bone stock),

Table 2 Measurements of reversible micromotion and irreversible migration after 100,000 loading cycles up to $1600 \mathrm{~N}$

\begin{tabular}{|c|c|c|c|c|}
\hline Implant & Mean & SD & Min & Max \\
\hline \multicolumn{5}{|c|}{ Axial Micromotion $(\mathrm{S} 1)[\mu \mathrm{m}](p=0.23)$} \\
\hline Optimys & 5.3 & 3.9 & 2.2 & 12.8 \\
\hline TwinSys & 9.3 & 6.6 & 2.8 & 17.2 \\
\hline \multicolumn{5}{|c|}{ Rotational Micromotion $(\mathrm{S} 2)\left[{ }^{\circ}\right](p=0.44)$} \\
\hline Optimys & 0.03 & 0.02 & 0.02 & 0.04 \\
\hline TwinSys & 0.04 & 0.02 & 0.01 & 0.07 \\
\hline \multicolumn{5}{|c|}{ Axial Migration $(\mathrm{S} 1)[\mu \mathrm{m}](p=0.22)$} \\
\hline Optimys & -20.4 & 38.3 & -92.7 & 8.7 \\
\hline TwinSys & -61.4 & 92.8 & -234.4 & 25.4 \\
\hline \multicolumn{5}{|c|}{ Rotational Migration $(\mathrm{S} 2)\left[^{\circ}\right](p=0.09)$} \\
\hline Optimys & 0.003 & 0.04 & -0.05 & 0.04 \\
\hline TwinSys & 0.09 & 0.12 & -0.10 & 0.24 \\
\hline
\end{tabular}

Table 3 Fracture load (Fmax) inducing a periprosthetic fracture in both stem types

\begin{tabular}{llllll}
\hline Donor & \multicolumn{2}{l}{ Optimys } & & & \multicolumn{2}{l}{ TwinSys } \\
\cline { 2 - 3 } \cline { 5 - 5 } \cline { 5 - 5 } & Fmax $(N)$ & Fracture type & & Fmax $(N)$ & Fracture type \\
\hline 1 & 2751 & B3 & 2912 & B3 \\
2 & 2885 & B3 & 2463 & C \\
3 & 3499 & B3 & 2945 & C \\
4 & 2730 & B3 & 3076 & B3 \\
5 & 3410 & B3 & 3550 & C \\
6 & 3099 & B3 & 4012 & C \\
Mean & 3062 & & 3160 & \\
SD & 332 & & 544 & \\
\hline
\end{tabular}

whereas 4 out of 6 conventional stems suffered a periprosthetic fracture according to type $\mathrm{C}$ (well below the tip of the stem). Figures 3, 4a, b exemplify the fracture pattern of periprosthetic fractures induced in both stem designs under controlled conditions.

\section{Discussion}

The aim of this biomechanical in vitro study was to compare the primary stability and maximum fracture load of a newly developed cemented short stem with a clinically proven cemented conventional stem (twinSys) [26]. Our results show that the shorter curved implant design does not negatively influence primary stability and maximum fracture load. However, we found a clear difference in fracture pattern. The short stems fractured according to Vancouver type B3 whereas the conventional stems, except for two preparations, fractured according to type $\mathrm{C}$.

To date, only few studies regarding cemented shorter femoral stems in THA can be found and none, which correspond to the design concept of the present study. Recently, Santori et al. published their 14-year experience with a cemented short stem [31]. However, given that this implant is a derivative of the Exeter straight stem philosophy and has just been shortened, the comparability to the philosophy of new-generation, calcar-guided short stems is limited. The design of the Friendly short stem (LimaCorporate, San Daniele Friuli, Italy) requires the addition of proximal and distal centralizers in the attempt of attaining a 2-mm cement mantle all around the stem. As stated in our recent investigation regarding cementation techniques in contemporary, calcarguided THA, a line-to-line technique best supports the philosophy of the more individualized implantation technique, compared to most cemented conventional femoral implants [25]. In vitro, it was found to be equivalent to the standard cementation technique using an undersized stem. However, the mid- and long-term results presented by Santori et al. 
Fig. 3 a, b Fracture pattern of periprosthetic fractures induced in both groups. All short stems showed proximal fractures according to Vancouver type B3 (a), 4 out of 6 straight stems showed Vancouver type $\mathrm{C}$ fractures (b)

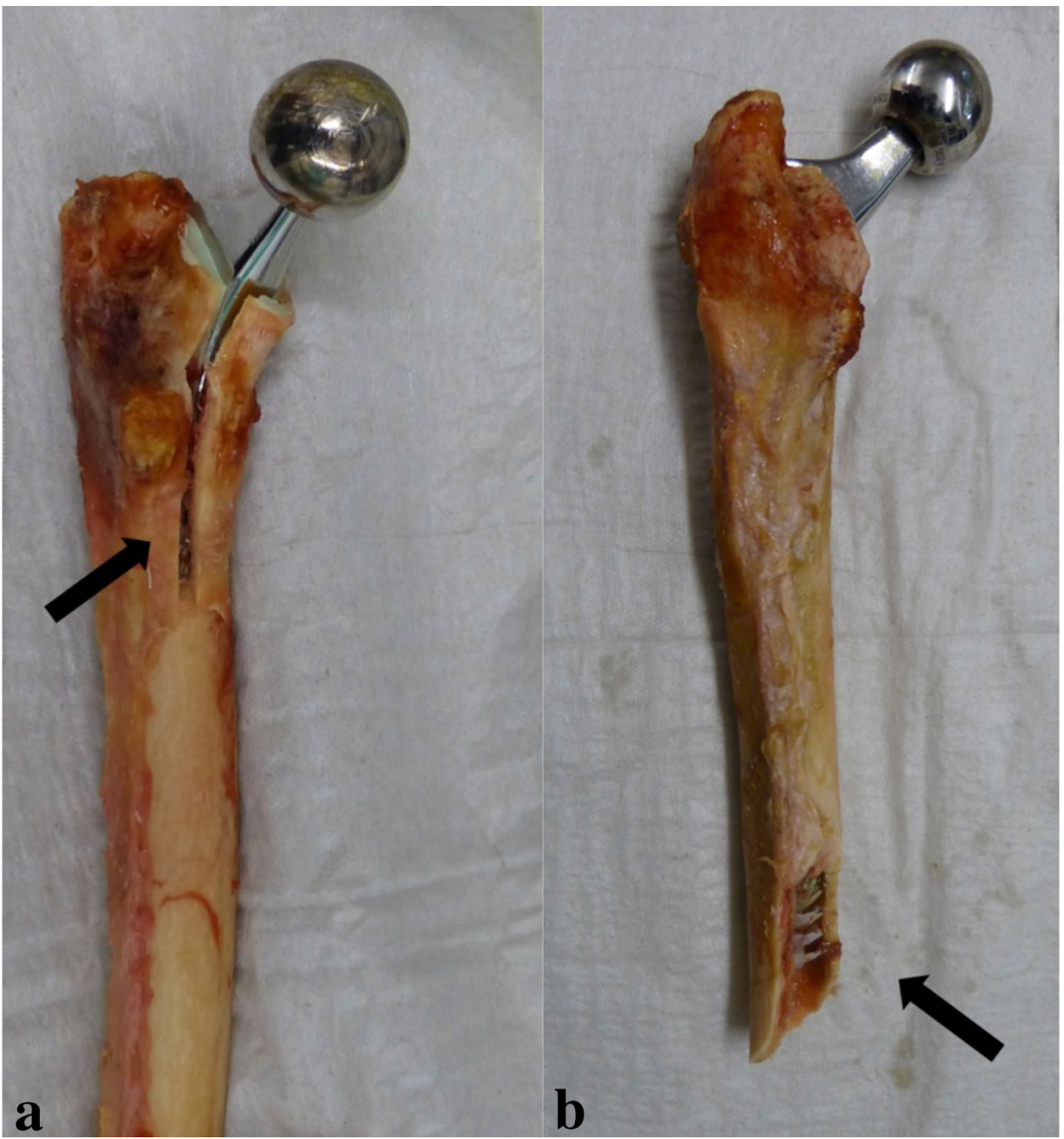

suggest a high reliability of a short, polished and tapered cemented stem without any drawbacks, compared to the conventional sized implants, being obvious [31].

Regarding existing literature involving shorter cemented stems, a second report can be found. Choy et al. presented their experience from the Australian Orthopaedic Association National Joint Replacement Registry (AOANJRR) regarding a 7-year follow-up of Exeter short stems compared to standard-length Exeter stems [32]. No significant difference was found in the cumulative percent revision rate in the short-stem group, compared with the standard-length stems, despite its use in a greater proportion of potentially more difficult hip dysplasia cases. Again, the comparability to the stem design, which was used in the present study, is severely restricted.

The concept of calcar-guided short-stem THA has the potential to preserve bone and soft tissue, by reconstructing the individual anatomy of the patient the best [33]. Furthermore, given a facilitated and less traumatic implantation technique, intraoperative blood loss can be reduced [18].
Recent studies provided beneficial mid-term clinical results of uncemented short stems compared to conventional stem designs along with decreased intraoperative complication rates [19, 20, 34, 35]. Especially neck-sparing short stems seem to have better maintenance of bone mineral density changes compared to conventional implants [35]. Furthermore, there are promising results regarding micromotion in vitro measurements, as well as clinical mid-term results of stem migration patterns and patient-reported outcome measures [24, 36, 37]. It remains unknown, if those potential advantages may be transferred also to the concept of cemented short-stem THA.

The present biomechanical investigation, however, resulted in equivalent results regarding primary stability and maximum fracture load of the newly developed cemented short stem compared to the well-established cemented conventional stem. This is in line with our prior results analyzing the uncemented version of the short stem (optimys), compared to a well-established uncemented conventional stem using the same study protocol [27]. A less pronounced 
Fig. 4 a, b Anteroposterior radiograph of the periprosthetic femoral fracture with consecutive stem loosening of a cemented short stem (a). Anteroposterior radiograph of the fracture of the femur with a cemented conventional stem (b) $\mathbf{a}$
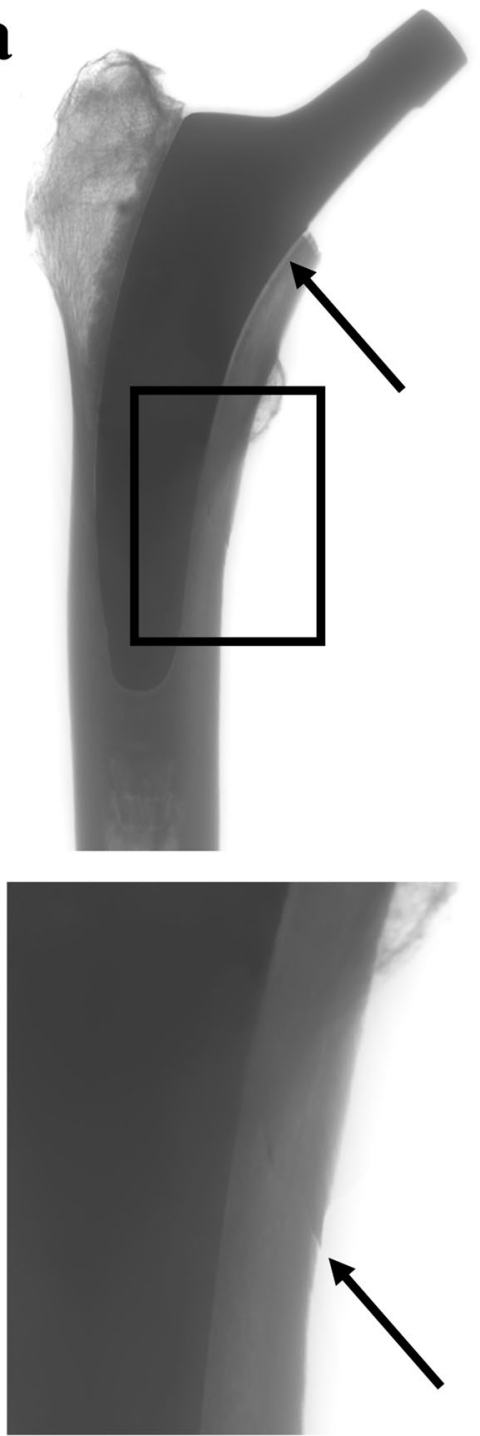

b

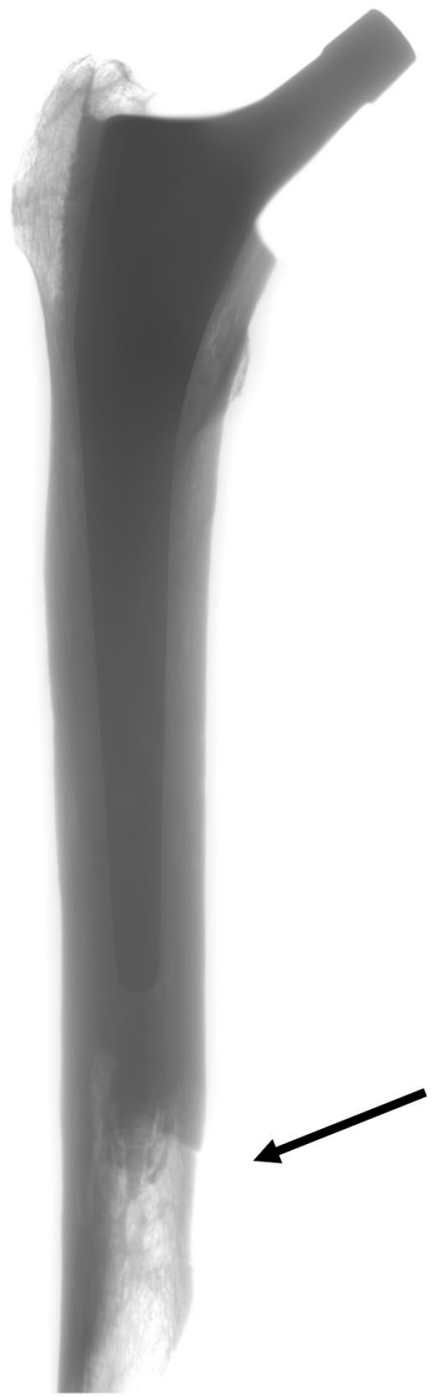

axial and rotational irreversible migration was found for the uncemented short stem, confirming the triple-taper design leads to sufficient stability. In isolated specimens of both stem designs, the measurements showed positive values with regard to migration in axial direction, which in principle would correspond to an implant migration out of the femur. This phenomenon could be explained by a slight tilting of the implant and consecutive elevation of the implant shoulder, on which the displacement transducer was positioned.

In contrast, biomechanical studies of cementless femoral implants showed lower load at failure of shorter stem designs $[38,39]$. A cadaver model comparing a double-wedged conventional stem with the Nanos short stem (Smith\&Nephew, Marl, Germany) found an increased load at failure for the conventional stem design up to $20 \%$ [38]. All specimens of this study suffered a type B2 fracture compromising the medial wall. Gabarre et al. studied the load transmission of the Minihip stem (Corin, Cirencester, United Kingdom) in a finite element model and found a lever effect with high compressive stresses in areas of the stem in contact with bone [40]. This implant follows a neck-sparing concept similar to the uncemented optimys. Lateral loading is also supported by bone mineral density measurements for both implants $[41,42]$. This could explain decreased fracture load and the fact, that mainly type b2 fractures were observed. However, even small design differences have significant influence on load transmission [43]. Furthermore, cemented stem fixation significantly influences load transmission of the implant in the proximal femur [44]. A biomechanical investigation of Thomsen et al. compared maximum fracture loads and fracture patterns of cemented and uncemented conventional stems in non-osteoporotic bone [45]. The maximum fracture load was found to be significantly higher for cemented stems. Fracture patterns corresponded to Vancouver type B fractures in uncemented stems and Vancouver type $\mathrm{C}$ fractures in cemented stems. In the present study, the Vancouver 
type $\mathrm{C}$ fracture pattern can be confirmed for cemented conventional stems. For the cemented short stem, however, the Vancouver type B3 pattern has to be acknowledged in all cases. A different fracture pattern of cemented femoral stems was observed in a biomechanical sawbone model [46]. Measurements showed a significantly lower torque to failure of a shortened Exeter stem compared to the conventional stem length. The authors conclude that both stems are safe to use as the torque to failure was 7-10 times higher than seen in activities of daily life. Furthermore, the authors observed only Vancouver type B2 fractures in both stem models. However, the test model included a single torsional torque which was applied by a material-testing machine until fracture occurred. A similar test setup with lateral load published by Klasan et al. compared a cemented and cementless double-tapered stem with conventional length in a biomechanical cadaver model [47]. The authors found an increased load-to-failure force by $25 \%$ for the cemented version. Similar to the above-mentioned study, they only observed fractures at the stem level for both implants with consecutive stem loosening. Our test setup included combined axial load and torsional torque, produced by tilting the preparations in the frontal $\left(8^{\circ}\right)$ and sagittal $\left(6^{\circ}\right)$ plane, which correspond to the conditions of a single-leg stand [48]. Furthermore, only specimens with reduced bone quality were used. This could explain the different results to our observations.

Some limitations have to be acknowledged. The simulation of the first 6 weeks of loading, only allows conclusions to be drawn about the early stage following implantation. Mid-term and long-term characteristics of cemented short stems most likely can only be obtained in a clinical setup in vivo. Furthermore, in vitro models always simplify in vivo conditions. Muscle forces on the hip joint could not be taken into consideration, resulting only in a "worst case" scenario for proximal loading, however, featuring the advantage of high reproducibility.

\section{Conclusions}

The present in vitro study demonstrates that the concept of a cemented calcar-guided short stem can be further pursued. When comparing the cemented short-stem concept to a well-established cemented conventional stem in the present test setting, no significant differences were found regarding primary stability and fracture load. However, a clear difference in the fracture pattern has to be acknowledged. Further investigations should include a clinical observational study, to confirm the present results under clinical conditions in vivo.

Acknowledgements We acknowledge the assistance of Patrizia Horny in data management and in preparing the illustrations.
Funding Open Access funding enabled and organized by Projekt DEAL. The study was financially supported by Mathys Ltd. No other funding was received.

\section{Declarations}

Conflict of interest KPK reports personal fees and non-financial support from Mathys Ltd. HR reports paid presentations for Smith \& Nephew Co. and Mathys Ltd. All the other authors declare, that they have no conflicts of interest.

Ethical approval Institutional review board approval was obtained for this study. All the procedures performed in studies involving human participants were in accordance with the ethical standards of the institutional research committee and with the 1964 Helsinki Declaration and its later amendments or comparable ethical standards.

Open Access This article is licensed under a Creative Commons Attribution 4.0 International License, which permits use, sharing, adaptation, distribution and reproduction in any medium or format, as long as you give appropriate credit to the original author(s) and the source, provide a link to the Creative Commons licence, and indicate if changes were made. The images or other third party material in this article are included in the article's Creative Commons licence, unless indicated otherwise in a credit line to the material. If material is not included in the article's Creative Commons licence and your intended use is not permitted by statutory regulation or exceeds the permitted use, you will need to obtain permission directly from the copyright holder. To view a copy of this licence, visit http://creativecommons.org/licenses/by/4.0/.

\section{References}

1. Knight SR, Aujla R, Biswas SP (2011) Total hip arthroplastyover 100 years of operative history. Orthop Rev (Pavia) 3:e16. https://doi.org/10.4081/or.2011.e16

2. The Swedish hip arthroplasty register annual report 2017. https:// registercentrum.blob.core.windows.net/shpr/r/Eng_Arsrapport 2017_Hoftprotes_final-Syx2fJPhMN.pdf. Accessed 13 Mar 2021

3. The Norwegian arthroplasty register annual report 2018. http://nrlweb.ihelse.net/eng/Rapporter/Report2018_english.pdf. Accessed 13 Mar 2021

4. National Joint Registry (NJR) for England, Wales, Northern Ireland and the Isle of Man 2018 Annual Report. https://www.hqip. org.uk/wp-content/uploads/2018/11/NJR-15th-Annual-Report2018.pdf. Accessed 13 Mar 2021

5. Australian Orthopaedic Association National Joint Registry annual report 2018. https://aoanjrr.sahmri.com/documents/10180/ 576950/Hip\%2C\%20Knee\%20\%26\%20Shoulder\%20Arthroplasty. Accessed 13 Mar 2021

6. The New Zealand Joint Registry annual report 2017. https://nzoa. org.nz/sites/default/files/DH8152_NZJR_2018_Report_v6_4Decv 18.pdf. Accessed 13 Mar 2021

7. Sidler-Maier CC, Waddell JP (2015) Incidence and predisposing factors of periprosthetic proximal femoral fractures: a literature review. Int Orthop 39:1673-1682. https://doi.org/10.1007/ s00264-015-2721-y

8. Bozic KJ, Lau E, Ong K, Chan V, Kurtz S, Vail TP, Rubash HE, Berry DJ (2014) Risk factors for early revision after primary total hip arthroplasty in Medicare patients. Clin Orthop Relat Res 472:449-454. https://doi.org/10.1007/s11999-013-3081-9 
9. Berry DJ (1999) Epidemiology: hip and knee. Orthop Clin North Am 30:183-190

10. Rayan F, Haddad F (2010) Periprosthetic femoral fractures in total hip arthroplasty - a review. Hip Int 20:418-426

11. Springer BD, Etkin CD, Shores PB, Gioe TJ, Lewallen DG, Bozic KJ (2019) Perioperative periprosthetic femur fractures are strongly correlated with fixation method: an analysis from the American joint replacement registry. J Arthroplasty. https://doi.org/10. 1016/j.arth.2019.02.004

12. Tanzer M, Graves SE, Peng A, Shimmin AJ (2018) Is cemented or cementless femoral stem fixation more durable in patients older than 75 years of age? A comparison of the best-performing stems. Clin Orthop Relat Res 476:1428-1437. https://doi.org/10.1097/ 01.blo.0000533621.57561.a4

13. Patel RM, Stulberg SD (2014) The rationale for short uncemented stems in total hip arthroplasty. Orthop Clin North Am 45:19-31. https://doi.org/10.1016/j.ocl.2013.08.007

14. Feyen H, Shimmin AJ (2014) Is the length of the femoral component important in primary total hip replacement. Bone Joint $\mathrm{J}$ 96-B:442-448. https://doi.org/10.1302/0301-620X.96B4.33036

15. Khanuja HS, Banerjee S, Jain D, Pivec R, Mont MA (2014) Short bone-conserving stems in cementless hip arthroplasty. J Bone Joint Surg Am 96:1742-1752. https://doi.org/10.2106/ JBJS.M.00780

16. Giardina F, Castagnini F, Stea S, Bordini B, Montalti M, Toni A (2018) Short stems versus conventional stems in cementless total hip arthroplasty: a long-term registry study. J Arthroplasty 33:1794-1799. https://doi.org/10.1016/j.arth.2018.01.005

17. Hossain F, Konan S, Volpin A, Haddad FS (2017) Early performance-based and patient-reported outcomes of a contemporary taper fit bone-conserving short stem femoral component in total hip arthroplasty. Bone Joint J 99-B:49-55. https://doi.org/10. 1302/0301-620X.99B4.BJJ-2016-1291.R1

18. Hochreiter J, Hejkrlik W, Emmanuel K, Hitzl W, Ortmaier R (2017) Blood loss and transfusion rate in short stem hip arthroplasty. A comparative study. Int Orthop 41:1347-1353. https:// doi.org/10.1007/s00264-016-3365-2

19. Molli RG, Lombardi AV Jr, Berend KR, Adams JB, Sneller MA (2012) A short tapered stem reduces intraoperative complications in primary total hip arthroplasty. Clin Orthop Relat Res 470:450-461. https://doi.org/10.1007/s11999-011-2068-7

20. van Oldenrijk J, Molleman J, Klaver M, Poolman RW, Haverkamp D (2014) Revision rate after short-stem total hip arthroplasty: a systematic review of 49 studies. Acta Orthop 85:250-258. https://doi.org/10.3109/17453674.2014.908343

21. Shin YS, Suh DH, Park JH, Kim JL, Han SB (2016) Comparison of specific femoral short stems and conventional-length stems in primary cementless total hip arthroplasty. Orthopedics 39:e311317. https://doi.org/10.3928/01477447-20160222-04

22. Gruner A, Heller KD (2015) Patient selection for shorter femoral stems. Orthopedics 38:S27-32. https://doi.org/10.3928/ 01477447-20150215-53

23. Gkagkalis G, Goetti P, Mai S, Meinecke I, Helmy N, Bosson D, Kutzner KP (2019) Cementless short-stem total hip arthroplasty in the elderly patient-is it a safe option?: a prospective multicentre observational study. BMC Geriatr 19:112. https:// doi.org/10.1186/s12877-019-1123-1

24. Zimmerer A, Slouka S, Kinkel S, Fritz T, Weiss S, Sobau C, Miehlke W (2020) Comparison of short-stem with conventionalstem prostheses in total hip arthroplasty: an 8-year follow-up study. Arch Orthop Trauma Surg 140:1285-1291. https://doi. org/10.1007/s00402-020-03519-y

25. Kutzner KP, Freitag T, Bieger R, Reichel H, Pfeil J, Ignatius A, Durselen L (2018) Biomechanics of a cemented short stem: Standard vs. line-to-line cementation techniques. A biomechanical in-vitro study involving six osteoporotic pairs of human cadaver femurs. Clin Biomech (Bristol, Avon) 52:86-94. https:// doi.org/10.1016/j.clinbiomech.2018.01.004

26. Madorin K, Siepen W, Manzoni I, Stoffel KK, Ilchmann T, Clauss M (2019) Five-year prospective subsidence analysis of 100 cemented polished straight stems: a concise clinical and radiological follow-up observation. Orthop Rev (Pavia) 11:7984. https://doi.org/10.4081/or.2019.7984

27. Bieger R, Ignatius A, Reichel H, Durselen L (2013) Biomechanics of a short stem: in vitro primary stability and stress shielding of a conservative cementless hip stem. J Orthop Res 31:1180-1186. https://doi.org/10.1002/jor.22349

28. Schmalzried TP, Harris WH (1993) Hybrid total hip replacement. A 6.5-year follow-up study. J Bone Joint Surg Br 75:608-615

29. Gotze C, Steens W, Vieth V, Poremba C, Claes L, Steinbeck J (2002) Primary stability in cementless femoral stems: custommade versus conventional femoral prosthesis. Clin Biomech (Bristol, Avon) 17:267-273. https://doi.org/10.1016/s0268-0033(02) 00012-8

30. Rohlmann A, Mossner U, Hees G, Bergmann G, Kolbel R (1982) The stress on the femur, cement and implant following implantation of a hip prosthesis. Biomedizinische Technik Biomed Eng 27:291-302

31. Santori N, Falez F, Potestio D, Santori FS (2019) Fourteen-year experience with short cemented stems in total hip replacement. Int Orthop 43:55-61. https://doi.org/10.1007/s00264-018-4205-3

32. Choy GG, Roe JA, Whitehouse SL, Cashman KS, Crawford RW (2013) Exeter short stems compared with standard length Exeter stems: experience from the Australian Orthopaedic Association National Joint Replacement Registry. J Arthroplasty 28(103109):e101. https://doi.org/10.1016/j.arth.2012.06.016

33. Kutzner KP, Freitag T, Kovacevic MP, Pfeil D, Reichel H, Bieger R (2017) One-stage bilateral versus unilateral short-stem total hip arthroplasty: comparison of migration patterns using "Ein-BildRoentgen-Analysis Femoral-Component-Analysis." Int Orthop 41:61-66. https://doi.org/10.1007/s00264-016-3184-5

34. Kaipel M, Grabowiecki P, Sinz K, Farr S, Sinz G (2015) Migration characteristics and early clinical results of the NANOS(R) short-stem hip arthroplasty. Wien Klin Wochenschr 127:375-378. https://doi.org/10.1007/s00508-015-0756-0

35. Sivaloganathan S, Maillot C, Harman C, Villet L, Riviere C (2020) Neck-sparing short femoral stems: a meta-analysis. Orthop Traumatol Surg Res. https://doi.org/10.1016/j.otsr.2020.05.004

36. Drosos GI, Touzopoulos P (2019) Short stems in total hip replacement: evidence on primary stability according to the stem type. Hip Int 29:118-127. https://doi.org/10.1177/1120700018811811

37. Jahnke A, Wiesmair AK, Fonseca Ulloa CA, Ahmed GA, Rickert M, Ishaque BA (2020) Outcome of short- to medium-term migration analysis of a cementless short stem total hip arthroplasty using EBRA-FCA: a radiological and clinical study. Arch Orthop Trauma Surg 140:247-253. https://doi.org/10.1007/ s00402-019-03315-3

38. Klasan A, Baumlein M, Dworschak P, Bliemel C, Neri T, Schofer MD, Heyse TJ (2019) Short stems have lower load at failure than double-wedged stems in a cadaveric cementless fracture model. Bone Joint Res 8:472-480. https://doi.org/10.1302/2046-3758. 810.BJR-2019-0051.R1

39. Jakubowitz E, Seeger JB, Lee C, Heisel C, Kretzer JP, Thomsen MN (2009) Do short-stemmed-prostheses induce periprosthetic fractures earlier than standard hip stems? A biomechanical exvivo study of two different stem designs. Arch Orthop Trauma Surg 129:849-855. https://doi.org/10.1007/s00402-008-0676-9

40. Gabarre S, Herrera A, Ibarz E, Mateo J, Gil-Albarova J, Gracia L (2016) Comparative analysis of the biomechanical behaviour of two cementless short stems for hip replacement: linea anatomic 
and minihip. PLoS ONE 11:e0158411. https://doi.org/10.1371/ journal.pone.0158411

41. Samy AM, El-Tantawy A (2019) Stem length in primary cementless total hip arthroplasty: does it make a difference in bone remodeling? Eur J Orthop Surg Traumatol 29:1235-1242. https:// doi.org/10.1007/s00590-019-02437-z

42. Hochreiter J, Mattiassich G, Ortmaier R, Steinmair M, Anderl C (2020) Femoral bone remodeling after short-stem total hip arthroplasty: a prospective densitometric study. Int Orthop 44:753-759. https://doi.org/10.1007/s00264-020-04486-0

43. Ruben RB, Fernandes PR, Folgado J (2012) On the optimal shape of hip implants. J Biomech 45:239-246. https://doi.org/10.1016/j. jbiomech.2011.10.038

44. Scheerlinck T, Casteleyn PP (2006) The design features of cemented femoral hip implants. J Bone Joint Surg Br 88:14091418. https://doi.org/10.1302/0301-620X.88B11.17836

45. Thomsen MN, Jakubowitz E, Seeger JB, Lee C, Kretzer JP, Clarius M (2008) Fracture load for periprosthetic femoral fractures in cemented versus uncemented hip stems: an experimental in vitro study. Orthopedics 31:653
46. Morishima T, Ginsel BL, Choy GG, Wilson LJ, Whitehouse SL, Crawford RW (2014) Periprosthetic fracture torque for short versus standard cemented hip stems: an experimental in vitro study. J Arthroplasty 29:1067-1071. https://doi.org/10.1016/j.arth.2013. 10.016

47. Klasan A, Baumlein M, Bliemel C, Putnis SE, Neri T, Schofer MD, Heyse TJ (2019) Cementing of the hip arthroplasty stem increases load-to-failure force: a cadaveric study. Acta Orthop 90:445-449. https://doi.org/10.1080/17453674.2019.1634331

48. Bergmann G, Graichen F, Rohlmann A (1993) Hip joint loading during walking and running, measured in two patients. J Biomech 26:969-990. https://doi.org/10.1016/0021-9290(93)90058-m

Publisher's Note Springer Nature remains neutral with regard to jurisdictional claims in published maps and institutional affiliations. 